Research Article

\title{
Interface Bonding Properties between Nonwater Reaction Polyurethane Polymer Materials and Concrete
}

\author{
Xijun Zhang $\mathbb{D}^{1,2,3}$ Chaojie Wang $\mathbb{D D}^{1,2,3}$ Han Tian, ${ }^{4}$ and Mingsheng Shi $\mathbb{D}^{1,2,3,5}$ \\ ${ }^{1}$ School of Water Conservancy Engineering, Zhengzhou University, Zhengzhou 450001, China \\ ${ }^{2}$ National Local Joint Engineering Laboratory of Major Infrastructure Testing and Rehabilitation Technology, \\ Zhengzhou 450001, China \\ ${ }^{3}$ Collaborative Innovation Center of Water Conservancy and Transportation Infrastructure Safety, Henan, \\ Zhengzhou 450001, China \\ ${ }^{4}$ Guiyang Engineering Corporation Limited of Power China, Guizhou, Guiyang 550000, China \\ ${ }^{5}$ Southern Institute of Infrastructure Testing and Rehabilitation Technology, Guangdong, Huizhou 516000, China
}

Correspondence should be addressed to Chaojie Wang; wangyichaojie123@163.com

Received 2 June 2021; Revised 6 July 2021; Accepted 17 July 2021; Published 24 July 2021

Academic Editor: Jinyang $\mathrm{Xu}$

Copyright (C) 2021 Xijun Zhang et al. This is an open access article distributed under the Creative Commons Attribution License, which permits unrestricted use, distribution, and reproduction in any medium, provided the original work is properly cited.

\begin{abstract}
The concentric pushing method was used to study the bonding properties between polymer and concrete. This paper studied the influence of polymer density, environmental temperature, and moisture content of concrete between polymer and concrete on the bond strength. The results indicated that the bond failure of specimens occurred mainly when the polymer was pushed out. Furthermore, increasing the polymer density increases the bond strength at the polymer-concrete interface but decreases as the moisture content of the concrete increases. The environmental temperature affects the curing time, and the bond strength increases with increasing temperature. Under the same condition, the bond strength was influenced by the roughness of the interface. This study provides references for the construction design and enhances polymer materials and matrix application for repairing cracks in concrete dams.
\end{abstract}

\section{Introduction}

Hydraulic structures are prone to cracks and concentrated leak channels during construction or operation. Many dam damage cases are caused by crack penetration. When repairing cracks in concrete dams, surface sealing, insertion, and grouting methods are generally used [1]. The grouting method is the best method to solve such problems. The grout used can be divided into cement grouting and chemical grouting [2-4]. The cement grouting method relies on the pumping pressure of the grouting equipment to fill the crack and act as the plugging slurry. However, the cement material has a long setting time, which is unsuitable for emergency or engineering rescue. After solidification, the cement slurry converts to a brittle material, resulting in repeated cracking [5-7]. The chemical grouting method relies on the pressure of the equipment to pump the slurry to the cracks and fill the cracks through expansion force [8]. Epoxy resin and polyurethane are generally used in polymer chemical grouting materials $[9,10]$. Epoxy resin materials are similar to cement materials. After hardening, they are brittle and cannot withstand secondary cracking $[11,12]$. In contrast, the elasticity of the polyurethane slurry in a specific density range is superior to the elasticity of the dam body and has a good sealing effect [13].

With the increasing number of large dams and reservoirs, the commonly used methods of emptying reservoirs are too expensive for deep diseases. Underwater repair is a more feasible method. However, the underwater environment requires a higher standard for repairing materials. Cracks in the dam body in a deep water environment can be repaired using submersibles. This means that the performance of repairing materials faces the adverse conditions of low temperature and wet interface [14-16]. Many 
researchers have conducted several studies on this topic $[17,18]$. Li et al. developed a polyurethane elastic sealing material and studied its characteristics such as water resistance, chemical resistance, and freeze-thaw resistance. The results showed that the material had high tensile bond strength (over $0.55 \mathrm{MPa}$ ) after a long-term water immersion test and a high elastic recovery rate $[11,19]$. Sun et al. developed underwater crack grouting materials and used simulation models to conduct detailed experiments on their technology. As a result, they suggested a set of underwater crack repair alternatives and techniques [20]. Zou et al. studied the effects of various ambient temperatures, moisture content, and mixing time on the bonding properties of polyurethane sealing materials. The results showed that the bonding performance increases with extended mixing time. Ambient temperature and moisture content are negatively related to bond strength [21]. The interaction between the polymer and civil engineering structures dramatically influences the mechanical properties of the structure. The strength of the polymer-structure interface is one of the most important parameters in engineering design. However, the most common bond strength testing methods for cement concrete materials are the pull-out and push-in methods [22-24]. Two-component nonaqueous reactive polyurethane materials are widely used for dam antiseepage repair due to their excellent properties [25], but their bonding with concrete has not been thoroughly studied [26]. The functional performance of a two-component polyurethane material after caulking depends on the interfacial moisture content, ambient temperature, and polymer density. In this paper, the bonding performance of two-component polyurethane material and concrete was studied by moisture content, the ambient temperature of the interface, and polymer density. It is crucial to improve the underwater construction technology of polyurethane grouting materials $[27,28]$.

\section{Experiment}

2.1. Materials and Model Design. The polymer was a twocomponent polymer that reacted and foamed. Component A consisted of isocyanates and polyisocyanates, and component B consisted of polyols and additives. Materials A and B were mixed and injected into steel models by a grouting gun. For polymer materials with densities of $0.1,0.12,0.2,0.29$, $0.4,0.6,0.8,0.83$, and $1.2 \mathrm{~g} / \mathrm{cm}^{3}$, the polymer density was controlled by mass. The C60 concrete was used in the test. The test pieces of this experiment were based on a standard permeability test piece (upper bottom, $185 \mathrm{~mm}$, lower bottom, $175 \mathrm{~mm}$, and height, $150 \mathrm{~mm}$ ) [29]. The center was preset with a hollow cylinder with a diameter of $90 \mathrm{~mm}$ filled with polymer (as shown in Figure 1(a)).

The polymer generates high temperatures and large expansion forces during the reaction [30]. Therefore, the specimens were placed in a special steel cylinder, and the top and bottom were connected using a flange plate and fixed with bolts. As shown in Figure 1(b), the position of the grouting hole was located at the center of the flange, and the venting hole was located at a short distance from the side of the grouting hole.
2.2. Specimen. In this test, 120 specimens were created to examine the bond strength between the polymer and concrete, mainly considering three parameters: concrete interface temperature, moisture content, and polymer density (as shown in Table 1). Hollow cylindrical specimens were used for the test. As shown in Figure 2, the concrete adopted a standard impermeability test model (upper, $185 \mathrm{~mm}$, lower, $175 \mathrm{~mm}$, and height, $150 \mathrm{~mm}$ ). First, the center was cut, and a PVC pipe with a diameter of $90 \mathrm{~mm}$ was inserted to reserve a hole for the polymer. The prepared concrete was then poured and removed from the mold, and, 28 days after standard curing, the specimens were soaked in groups. The time control was divided into $0 \mathrm{~h}, 3 \mathrm{~h}, 10 \mathrm{~h}$, and $24 \mathrm{~h}$. The soaked specimens were wrapped in plastic wrap and placed in a constant temperature test room $\left(0^{\circ} \mathrm{C}-15^{\circ} \mathrm{C}\right)$ for $24 \mathrm{~h}$. After applying butter, they were placed in a steel cylinder. They were then covered with upper and lower flanges, bolts were tightened, and the grouting density was changed by controlling the grouting mass. As a result, the polymer expanded rapidly within the model, discharging air through the overflow hole. After grouting for 1 hour, all samples were unmolded and placed in the laboratory until testing.

After prolonged immersion, cracks in the concrete may be fully saturated. In this experiment, specimens were made using C60 grade high-strength concrete. The moisture content was measured as shown in Figure 3. From the figure, it can be seen that the moisture content of the specimens increased sharply in the early stage after soaking in water, but the growth rate was slow after $24 \mathrm{~h}$. Therefore, the moisture content corresponding to the immersion time of 24 hours can be regarded as the saturated moisture content (about 2.66\%).

2.3. Experiment Method. Due to the short hole in the center of specimens, it was difficult to anchor the low-density specimens. The main test was the bonding properties of the interface between polyurethane polymer and concrete. Therefore, the concentric pull-out test was not adopted, and the bond strength was determined by the concentric pushing test shown in Figure 4 [31]. The specimens were placed on a test bench with a special steel ring substrate. The top of the pusher was made of an $85 \mathrm{~mm}$ diameter disc, the center of which was aligned with the sample. The universal testing machine was equipped with a strain acquisition system that collected continuous displacement. The maximum load of the universal test machine was $100 \mathrm{kN}$, the load speed was $0.1 \mathrm{kN} / \mathrm{s}$, and changes in load and displacement could be recorded automatically. Before official loading, we considered a preload of $1 \mathrm{kN}$ [32]. Loading was stopped when the following happened: (1) the central hole of the concrete specimen was destroyed; (2) the polyurethane polymer core was cracked and damaged; and (3) the polyurethane polymer core did not slip along the concrete interface. Since the maximum load $P$ was measured using a load cell with an accuracy of $0.01 \mathrm{kN}$, the average bond stress $T$ can be taken as into account $T=P / A$. The average bond strengths of the three groups of parallel specimens were taken as measurement values for those experimental specimens. 


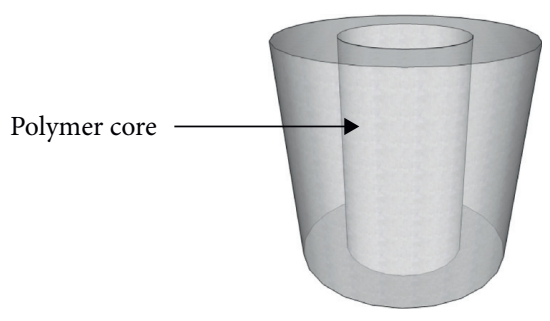

(a)

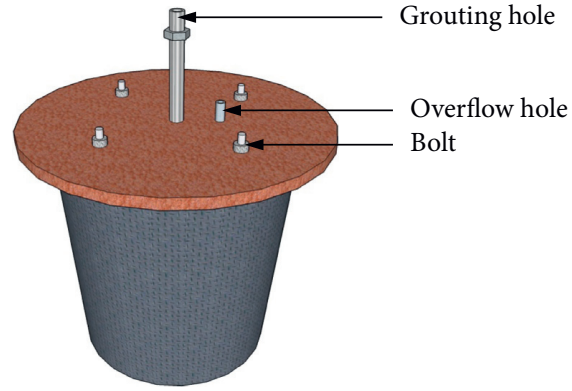

(b)

Figure 1: (a) Test piece schematic. (b) Steel cylinder.

TABLE 1: The parameters related to specimens.

\begin{tabular}{|c|c|c|c|c|}
\hline Number & Density $\rho /\left(\mathrm{g} / \mathrm{cm}^{3}\right)$ & Soaking time $(\mathrm{h})$ & Temperature $\left({ }^{\circ} \mathrm{C}\right)$ & Average moisture content (\%) \\
\hline $1-3$ & 0.6 & 0 & 0 & - \\
\hline $4-6$ & 0.6 & 0 & 5 & - \\
\hline $7-9$ & 0.6 & 0 & 10 & - \\
\hline $10-12$ & 0.6 & 0 & 15 & - \\
\hline $13-15$ & 0.6 & 3 & 0 & 0.98 \\
\hline $16-18$ & 0.6 & 3 & 5 & 0.98 \\
\hline $19-21$ & 0.6 & 3 & 10 & 1.01 \\
\hline $22-24$ & 0.6 & 3 & 15 & 1.02 \\
\hline $25-27$ & 0.6 & 10 & 0 & 0.83 \\
\hline$\ldots$ & $\ldots$ & $\ldots$ & $\ldots$ & $\ldots$ \\
\hline $37-39$ & 0.6 & 24 & 0 & 1.3 \\
\hline $40-42$ & 0.6 & 24 & 5 & 1.22 \\
\hline $43-45$ & 0.6 & 24 & 10 & 1.03 \\
\hline $46-48$ & 0.6 & 24 & 15 & 0.76 \\
\hline $49-51$ & 0.12 & 24 & 5 & 1.12 \\
\hline $52-54$ & 0.29 & 24 & 5 & 1.57 \\
\hline $55-57$ & 0.6 & 24 & 5 & 1.22 \\
\hline $58-60$ & 0.83 & 24 & 5 & 1.5 \\
\hline $61-63$ & 0.1 & 0 & 0 & - \\
\hline $64-66$ & 0.2 & 0 & 0 & - \\
\hline $67-69$ & 0.4 & 0 & 0 & - \\
\hline $70-72$ & 0.8 & 0 & 0 & - \\
\hline $73-75$ & 1.2 & 0 & 0 & - \\
\hline $76-78$ & 1.2 & 0 & 5 & - \\
\hline $79-81$ & 1.2 & 0 & 10 & - \\
\hline $82-84$ & 1.2 & 0 & 15 & - \\
\hline $85-87$ & 0.1 & 0 & 25 & - \\
\hline $88-90$ & 0.2 & 0 & 25 & - \\
\hline $91-93$ & 0.4 & 0 & 25 & - \\
\hline $94-96$ & 0.6 & 0 & 25 & - \\
\hline $97-99$ & 0.8 & 0 & 25 & - \\
\hline $100-102$ & 1.2 & 0 & 25 & - \\
\hline$\ldots$ & $\ldots$ & $\ldots$ & $\ldots$ & $\ldots$ \\
\hline $112-114$ & 1.2 & 24 & 0 & 1.92 \\
\hline $115-117$ & 1.2 & 24 & 5 & 2.18 \\
\hline $118-120$ & 1.2 & 24 & 15 & 2.42 \\
\hline
\end{tabular}

To ensure the accuracy of the experiments, each test piece in the table consists of three samples.

The specimens were classified into three groups to examine the effects of polymer density, prewetting of the concrete surface before grouting, and temperature after grouting on bond behavior. The impact of interfacial moisture on bond strength under dry and saturated conditions was evaluated in the first group. The temperature was $10^{\circ} \mathrm{C}$, and the polymer density was $0.6 \mathrm{~g} / \mathrm{cm}^{3}$. In the second group, specimens with temperatures of $0^{\circ} \mathrm{C}, 5^{\circ} \mathrm{C}$, $10^{\circ} \mathrm{C}$, and $15^{\circ} \mathrm{C}$ were tested to examine the effects of temperature. In the third group, samples with various polymer 


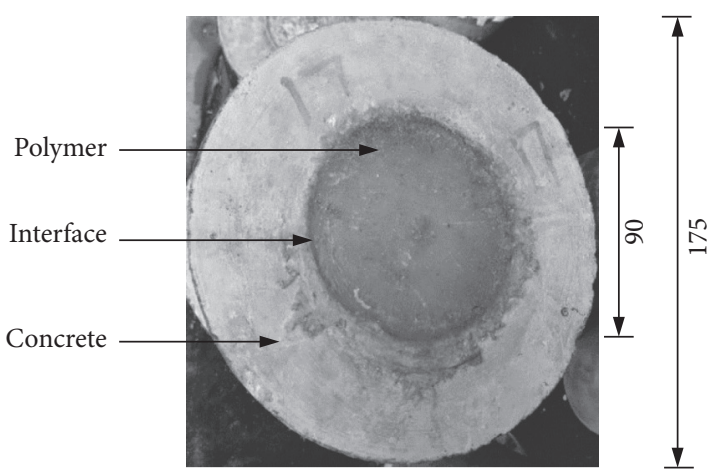

FIgURE 2: Details of bonding specimens (mm).

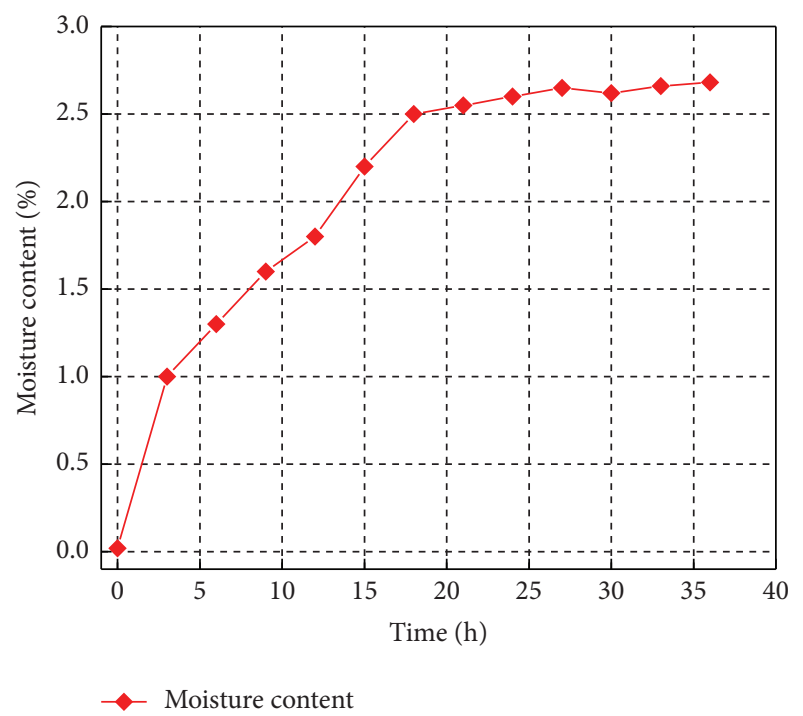

Figure 3: Moisture growth curve.

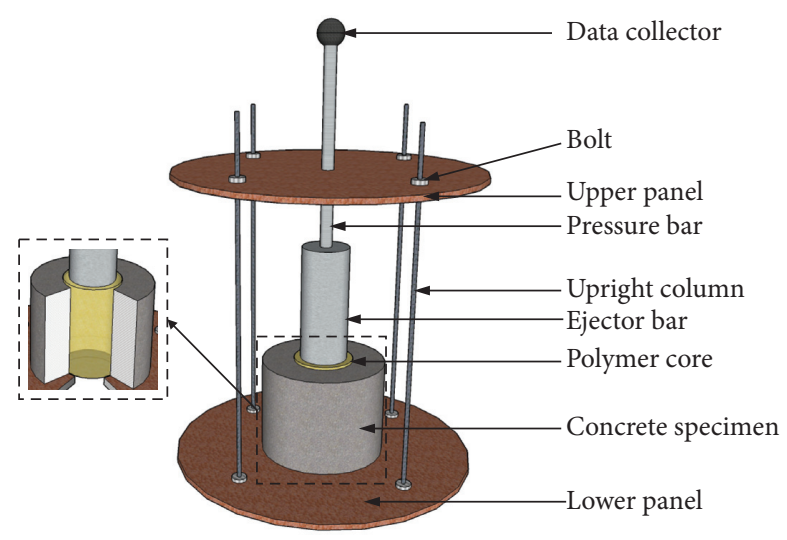

FIgURE 4: Experimental device. densities of $0.1,0.12,0.2,0.29,0.4,0.6,0.8,0.83$, and $1.2 \mathrm{~g} /$ $\mathrm{cm}^{3}$ were prepared to evaluate the effects of polymer densities.

\section{Results and Discussion}

Most of the 120 specimens in this test experienced slip damage at the polymer-concrete interface (as shown in Figure 5(a)). In addition, when a part of the annular concrete of the specimen was pushed out, it was partially damaged (as shown in Figure 5(b)). Some high-density specimens are damaged by the hardened surface of polyurethane, but this damage did not penetrate the polymer, and the polymer core was intact. It was found that the interface of the polymer was worn, and the uneven part of the surface was polished. The inner interface of the concrete was also worn, the concrete at the inner interface of the individual specimens was sheared, and the concrete skin was stuck off.

3.1. Average Compression. As shown in Figure 6, the compression value at the time of failure of the polymer bond in the center of specimens was recorded to determine the relationship between the compression value and the density. The results show that the greater the push-out forces for lowdensity specimens, the greater the compression deformation. The reason is that when the polymer density is low, many bubbles exist in the polymer, the compactness is low, and the compression deformation is large. The deformation of low-density specimens is greatly affected by the push-out force. The push-out force is proportional to the compression value for high-density specimens $\left(1.2 \mathrm{~g} / \mathrm{cm}^{3}\right)$. As a result, the slope of the density-compression curve is less than the slope of low-density specimens. In high-density polymers, the microscopic morphology can be interpreted as the formation of isolated high-density bubbles within the polymer. By decreasing the size of the bubbles, the wall thickness of the bubbles increases. In addition, the delicate and uniform cell structure enhances the resistance of the material to deformation (as shown in Figure 7(b)).

3.2. Polymer-Concrete Bond-Slip Characteristics. As shown in Figure 8, the slip of the load end and that of the free end are basically the same, but the free end displacement is slightly delayed. The free end load-displacement curve intersects the coordinate axis. This indicates that the load end slightly slips in the early stages of loading, and no failure is transmitted from the bond interface to the free end. Thus, there is no slip on the free end, and external loads are resisted mainly by chemical cementation at this stage. According to bond-slip characteristics, the entire development can be simply divided into three stages. 


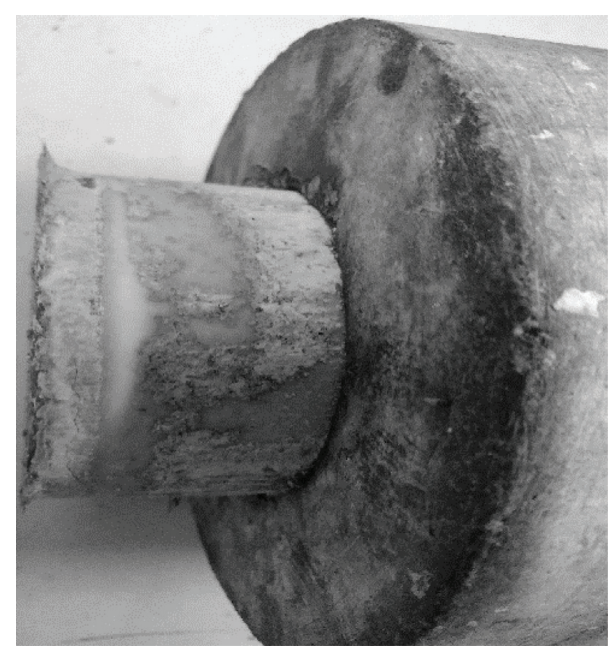

(a)

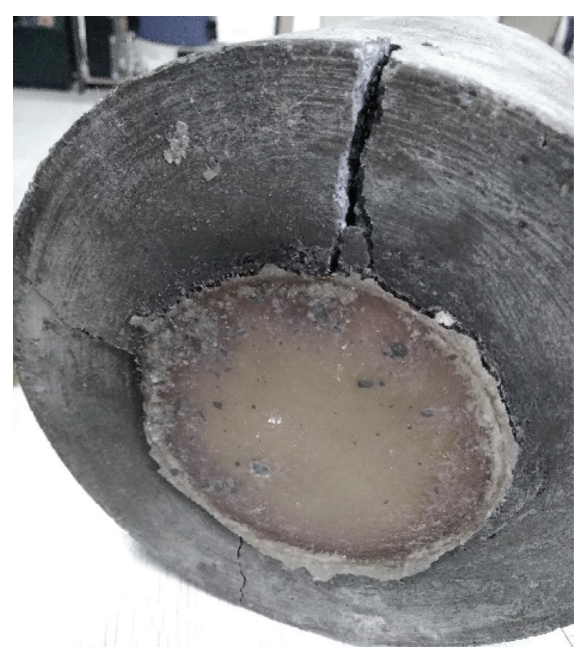

(b)

Figure 5: (a) A typical form of destruction. (b) Concrete fragmentation.

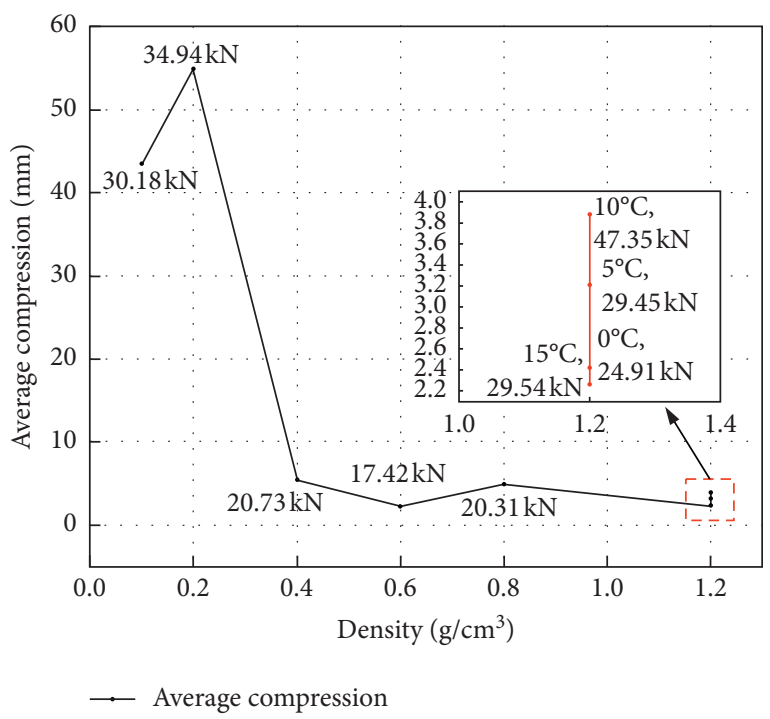

FigURE 6: Relationship between density and average compression.

3.2.1. Linear Slip Stage $(O A)$. In the OA stage, the loaddisplacement curve is approximately linear. The thrust is mainly resisted by friction and mechanical bite force at this stage, and the chemical bonding force no longer works. As a result, the displacement increases faster, and the displacement of the free end is slightly smaller than that of the load end.

3.2.2. Ejection Stage. As the load continues to increase, the concrete on the bonding interface is worn out, the amount of slip is further accelerated, the load-displacement curve tends to be flat, and the load eventually reaches its peak.

3.2.3. Thrust Decay Stage. As the amount of slip increases, the concrete surface that comes into contact with the polymer wears severely, reducing the friction and mechanical bite force and the corresponding thrust.
3.3. Bond Strength. This test uses the bond strength between polymer and concrete under normal temperature $\left(25^{\circ} \mathrm{C}\right)$ and dry conditions as a reference. Table 2 shows the trend of bond strength as a function of density.

3.3.1. Effect of Moisture Content. Cracks at certain engineering sites in dams are often moist because the water level constantly changes on rainy days and under the influence of open sluice gates [20]. Polyurethane materials are sensitive to the moisture level at the repair interface, which in turn affects the bond strength between the polyurethane polymer and the concrete on either side of the crack [33]. Specimens in Table 3 have the same density $\left(0.6 \mathrm{~g} / \mathrm{cm}^{3}\right)$ and interface temperature $\left(0^{\circ} \mathrm{C}\right)$. Four different wetting conditions were set, and soaking time was used as a screening condition for moisture levels. Using the moisture content as a quantitative index, the bond strength was measured as follows. It can be seen that the bond strength decreases with the increase of moisture levels (water content) under the same temperature condition, because the water reacted with isocyanate to form carbon dioxide to reduce the adhesion if the isocyanate in the two-component polyurethane material was less than $2 \%$ in the aqueous state. The reason may be that when the amount of isocyanate is small, the foam curing is not complete, and the structure of the cross-linking network is partly defective. At a temperature of $0^{\circ} \mathrm{C}$ and a polymer density of $0.6 \mathrm{~g} / \mathrm{cm}^{3}$, the bond strength of the specimens at the soaking times of $3 \mathrm{~h}$ and $24 \mathrm{~h}$ decreased by $75.2 \%$ and $84.3 \%$, respectively. Therefore, it is highly required to reduce the interfacial moisture between concrete and polymers in engineering applications. For example, a superplasticizer can be added to concrete to prevent a significant decrease in bond strength due to moisture [34].

3.3.2. Effect of Temperature. Figure 9 shows that, under the same conditions, the higher the temperature within a certain temperature range, the higher the bond strength. However, 


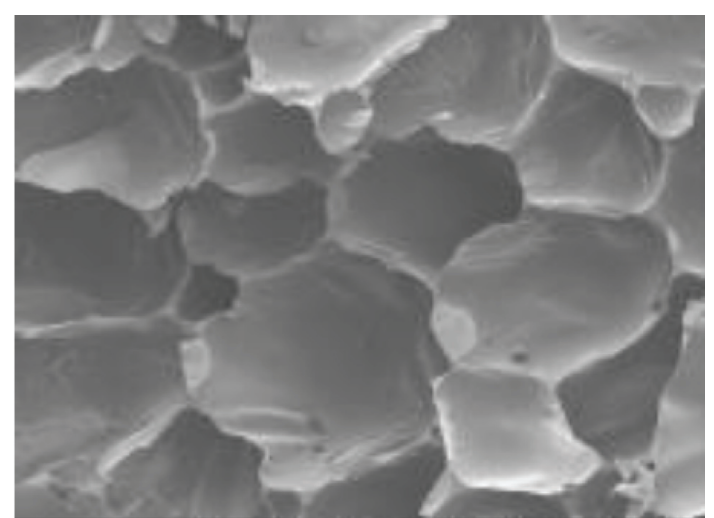

(a)

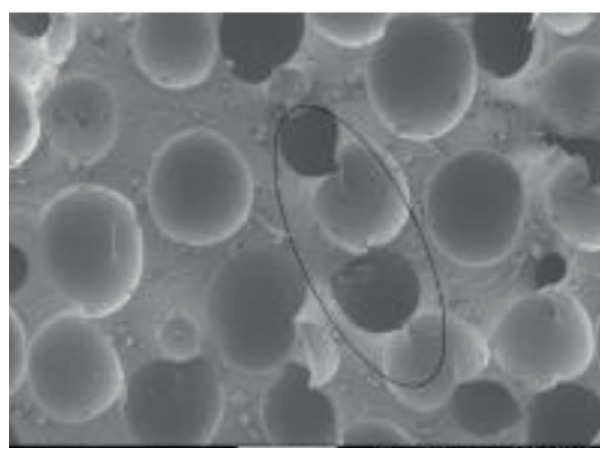

(b)

FIgURE 7: SEM images of the polymer at densities of (a) $0.15 \mathrm{~g} / \mathrm{cm}^{3}$ and (b) $0.57 \mathrm{~g} / \mathrm{cm}^{3}$.

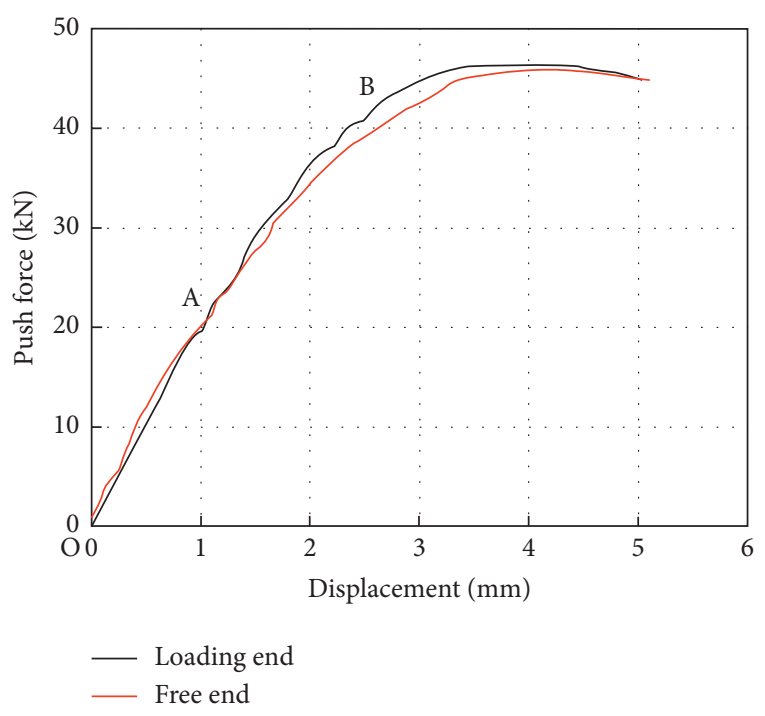

FIGURE 8: Bond-slip curves of the loading end and the free end.

TABLe 2: Relationship between bond strength and density.

\begin{tabular}{lcccccc}
\hline Density $\rho /\left(\mathrm{g} / \mathrm{cm}^{3}\right)$ & 0.1 & 0.2 & 0.4 & 0.6 & 0.8 & 1.2 \\
\hline Bond strength $(\mathrm{MPa})$ & 0.31 & 0.53 & 0.6 & 1.12 & 1.55 & 1.98 \\
\hline
\end{tabular}

under saturation conditions, the bond strength is reduced accordingly (as shown in Table 4). As can be seen from Table 5, the bond strength, corresponding to the temperature drop, decreased by $43.8 \%-57.1 \%$ in the dry state. The lower the temperature, the more significant the decrease. In addition, as the temperature drops, the bond strength decreases from $65.2 \%$ to $83 \%$. This is because the higher the temperature of the specimen, the slower the temperature loss of the polymer during the reaction and the lower the temperature shrinkage stress. On the other hand, at the concrete interface, the higher the temperature of the specimens, the denser the compaction. Therefore, differences between the reaction temperature of the low temperature specimens and the material in the reaction process are large, and temperature shrinkage stress is generated. After the reaction, the extrusion and cementation forces are offset by the temperature shrinkage stress, the concrete is disengaged from the concrete, and the bond force is reduced.

3.4. Effect of Polymer Density. To produce polymer water stop plugging, the effect of density on bond strength at low temperatures and under fully saturated interfacial conditions needs to be further investigated [35]. The interface temperature of the specimens is $5^{\circ} \mathrm{C}$, and it is fully saturated $(24 \mathrm{~h})$. The effect of polymer density on bond strength can be analyzed and compared to dry conditions. Figure 10 shows the relationship between bond strength and polymer density. Based on the linear fitting results, the bond strength between the polymer and the concrete interface is positively correlated with the polymer. The higher the density of the polymer, the higher the bond strength between the polymer and the concrete interface.

The absolute difference in the bond strength between the saturated and dry specimens between $0.1 \mathrm{~g} / \mathrm{cm}^{3}$ and $0.4 \mathrm{~g} /$ $\mathrm{cm}^{3}$ is not significant, with a mean reduction of about $3.8 \%$. However, the absolute difference in density between $0.4 \mathrm{~g} /$ $\mathrm{cm}^{3}$ and $1.5 \mathrm{~g} / \mathrm{cm}^{3}$ is 1.0 and it is significantly larger for $1.2 \mathrm{~g} /$ $\mathrm{cm}^{3}$. The reduction rate is large, ranging from $67.2 \%$ to $72.7 \%$. The difference between dense specimens $\left(1.2 \mathrm{~g} / \mathrm{cm}^{3}\right)$ is much more remarkable. The bond strength between fully saturated low-density specimens and high-density specimens is relatively concentrated, indicating that an increase in polymer density in the water has a limited effect on the growth of bond strength. There are two reasons for this phenomenon. As shown in Figure 7, when the polymer density is relatively low (Figure 7(a)), there are many bubble cells in the polymer, the radius of the bubbles becomes large, and the bubbles are squeezed together. On the other hand, the polymer is combined with the concrete through the thin walls of the bubble chamber, reducing the bond strength. The higher the polymer density (Figure 7(b)), the smaller the radius of the bubble and the thicker the walls. This increases the distance between the bubble chamber and the concrete. Therefore, at the polymer-concrete interface, the thick walls of the bubbles cells bond with the concrete, increasing the 
TABLE 3: Relationship between moisture content and bond strength.

\begin{tabular}{|c|c|c|c|c|c|c|}
\hline Number & Temperature $\left({ }^{\circ} \mathrm{C}\right)$ & $\begin{array}{c}\text { Moisture } \\
\text { content (\%) }\end{array}$ & $\begin{array}{l}\text { Ave. moisture } \\
\text { content (\%) }\end{array}$ & Soaking time $(\mathrm{h})$ & Bond strength (MPa) & Ave. bond strength $(\mathrm{MPa})$ \\
\hline \multirow{4}{*}{$1-3$} & 0 & 0 & 0 & 0 & 0.42 & 0.48 \\
\hline & & 0 & & & 0.56 & \\
\hline & & 0 & & & 0.46 & \\
\hline & 0 & 0.8 & 0.98 & 3 & 0.37 & 0.3 \\
\hline \multirow{3}{*}{$13-15$} & & 1.03 & & & 0.44 & \\
\hline & & 1.11 & & & 0.09 & \\
\hline & 0 & 0.95 & 0.83 & 10 & 0.29 & 0.71 \\
\hline \multirow{3}{*}{$25-27$} & & 0.47 & & & 0.64 & \\
\hline & & 1.08 & & & 1.12 & \\
\hline & 0 & 0.93 & 1.3 & 24 & 0.25 & 0.19 \\
\hline \multirow{2}{*}{$37-39$} & & 1.19 & & & 0.2 & \\
\hline & & 1.79 & & & 0.11 & \\
\hline
\end{tabular}

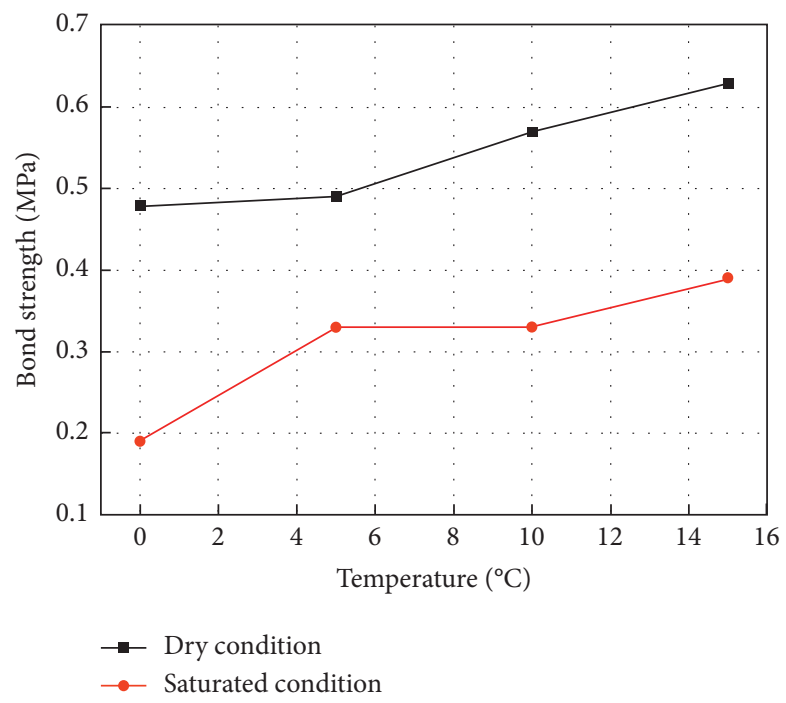

Figure 9: Relationship between temperature and bond strength.

TABle 4: Saturation conditions.

\begin{tabular}{lcccccc}
\hline Number & $\begin{array}{c}\text { Density } \rho /(\mathrm{g} / \\
\left.\mathrm{cm}^{3}\right)\end{array}$ & Soaking time $(\mathrm{h})$ & Temperature $\left({ }^{\circ} \mathrm{C}\right)$ & Ave. moisture content $(\%)$ & Bond strength $(\mathrm{MPa})$ & Reduction rate $(\%)$ \\
\hline $37-39$ & 0.6 & 24 & 0 & 1.3 & 0.19 & 83.0 \\
$40-42$ & 0.6 & 24 & 5 & 1.22 & 0.33 & 70.5 \\
$43-45$ & 0.6 & 24 & 10 & 1.03 & 0.33 & 70.5 \\
$46-48$ & 0.6 & 24 & 15 & 0.76 & 0.39 & 65.2 \\
\hline
\end{tabular}

TABLE 5: Dry condition.

\begin{tabular}{lcccccc}
\hline Number & $\begin{array}{c}\text { Density } \rho /(\mathrm{g} / \\
\left.\mathrm{cm}^{3}\right)\end{array}$ & Soaking time $(\mathrm{h})$ & Temperature $\left({ }^{\circ} \mathrm{C}\right)$ & Ave. moisture content $(\%)$ & Bond strength $(\mathrm{MPa})$ & Reduction rate $(\%)$ \\
\hline $1-3$ & 0.6 & 0 & 0 & - & 0.48 & 57.1 \\
$4-6$ & 0.6 & 0 & 5 & - & 0.49 & 5.57 \\
$7-9$ & 0.6 & 0 & 10 & - & 0.63 & 49.1 \\
$10-12$ & 0.6 & 0 & 15 & - & 43.8 \\
\hline
\end{tabular}

bond strength. In addition, the expansion force of the polymer increases with density. As a result, the intercalation and cementation of the polymer at the interface become stronger, resulting in higher bond strength [28]. The higher the density of the polymer, the higher the bond strength at the interface in a certain range. This means that the contact 


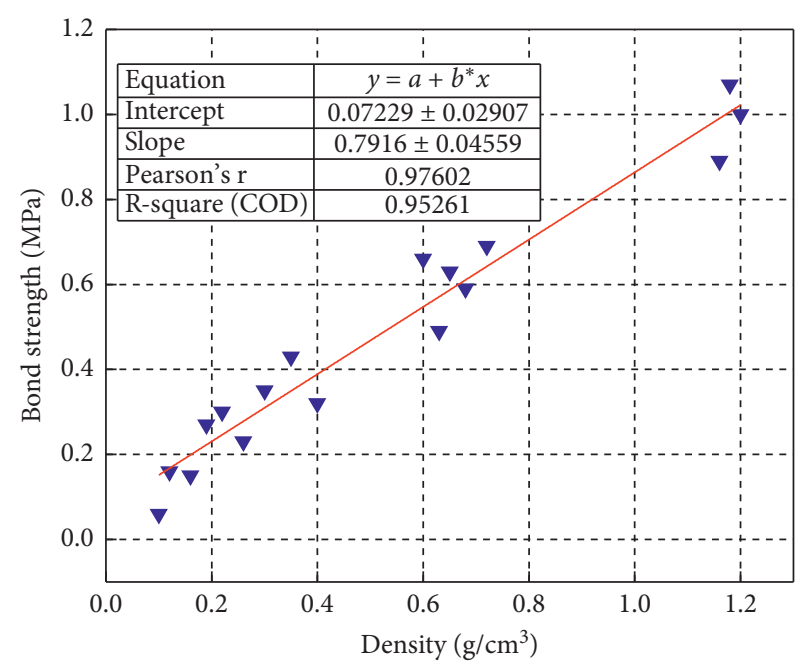

- Experimental data (saturated condition) Linear fitting (saturated condition)

(a)

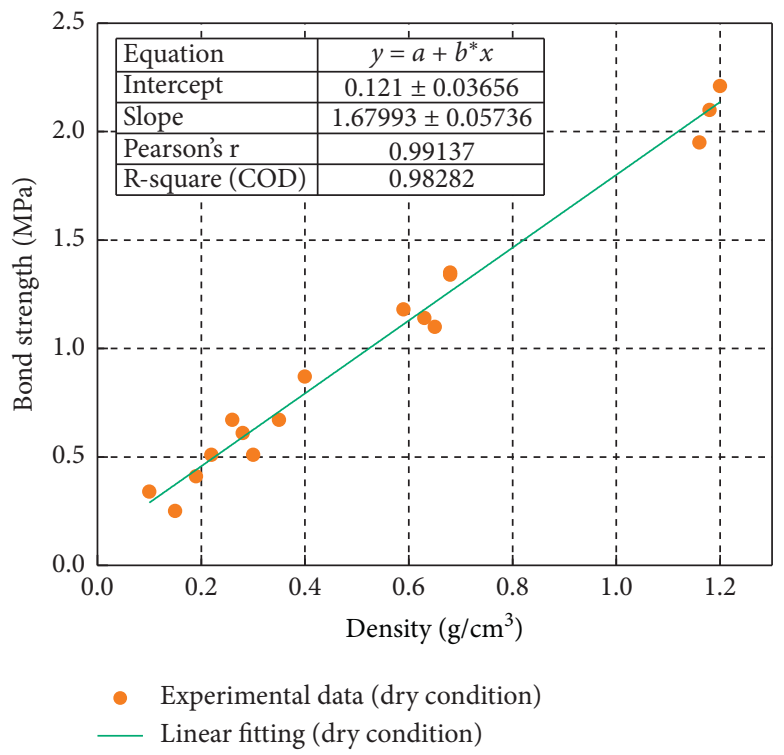

(b)

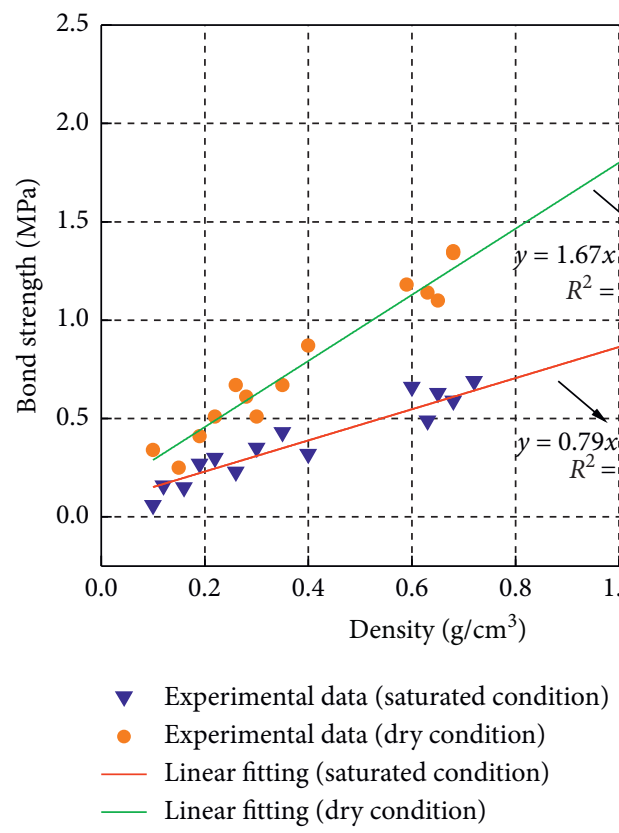

(c)

Figure 10: Relationship between polymer density and bond strength.

surface can withstand higher shear forces and pressures. However, the increase in polymer density has a limited effect on the growth of bond strength at the saturated interface. During the reaction, many bubbles are generated on the surface of the concrete, and the bond strength is significantly reduced due to intrusion. If the specimen polymer density exceeds a specific range, most of it will damage the concrete [36].

\section{Conclusion}

Through a concentric pushing test system for 120 adhesive specimens, the effects of temperature, density, and interfacial moisture on the bonding properties between polymers and concrete under special construction conditions were studied. From the results obtained, the following conclusions can be drawn:

(1) When fully saturated, increasing the polymer density has little effect on bond strength. In contrast, increased polymer density has a significant effect on bond strength under dry conditions.

(2) Interfacial moisture content is a significant factor affecting the bonding properties between the polymer and concrete. At the same interfacial temperature, the higher the interfacial moisture content, the 
lower the bond strength between the polymer and concrete. When the interface is completely saturated, the interfacial bond strength follows this rule, but the overall bond strength is lower than that of a dry interface. For dam concrete structures, reducing interfacial water content and increasing the mass of the polymer are effective methods to improve the bonding force between the polymer and concrete.

(3) The bond strength between the polymer interface and the concrete interface is much less than the shear resistance of the polymer itself. As a result, most of the polymer cores are intact and are mainly damaged by ejecting, with less damage to the inner surface of the concrete.

\section{Data Availability}

The data used to support the findings of this study are available from the corresponding author upon request.

\section{Conflicts of Interest}

The authors declare that they have no conflicts of interest.

\section{Authors' Contributions}

Mingsheng Shi conceptualized the study. Han Tian performed data curation. Xijun Zhang performed formal analysis. Mingsheng Shi was responsible for funding acquisition. Xijun Zhang developed the methodology. Xijun Zhang wrote the original draft. Chaojie Wang reviewed and edited the article.

\section{Acknowledgments}

This research was supported by "National Key R\&D Program of China" (2017YFC1502606), the National Natural Science Foundation of China (no. 51679219), Program for Guangdong Introducing Innovative and Entrepreneurial Teams (2016ZT06N340), and Science and Technology Project of Tibet Autonomous Region (XZ201801-GB-7).

\section{References}

[1] J. Conceio, F. Rui, M. Azenha, and M. Miranda, "A new method based on equivalent surfaces for simulation of the post-cooling in concrete arch dams during construction," Engineering Structures, vol. 209, Article ID 109976, 2020.

[2] C. J. Billington, "The underwater repair of concrete offshore structures," Protein and Peptide Letters, vol. 5, pp. 459-468, 1979.

[3] S. Kazemian and B. K. Bujang, "Assessment and comparison of grouting and injection methods in geotechnical engineering," European Journal of Scientific Research, vol. 52, pp. 243-247, 2009.

[4] B. Czupryński, J. Liszkowska, and J. Paciorek-Sadowska, "Modification of the rigid polyurethane-polyisocyanurate foams," Journal of Chemistry, vol. 2014, Article ID 130823, 12 pages, 2014.

[5] P. Hong pu, S. U. Yi-sheng, X. Guo-hong, C. Zong-ping, and N. I. Huan-cheng, "Study of bond force on polyurethane foam materal and fly ash concrete," Journal of Guangxi University, vol. 34, pp. 9-12, 2009.

[6] L. Hou-Tang, Preparation and Application of the New Polyurethane Adhensives, China Adhesives, Shanghai, China, 2005.

[7] Y. Wang and C. Zeng, "Shear behavior of wheat-concrete interface during monotonic and cyclic loading," Complexity, vol. 2019, Article ID 6792650, 15 pages, 2019.

[8] X. Yang, K. Zheng, L. Xu, and N. Liu, "Properties and applications of a new chemical grouting material," Advances in Civil Engineering, vol. 2020, Article ID 7191354, 10 pages, 2020.

[9] C. Yang-jie, X.-f. Zhang, X.-1. Lu, Q. Lu, and J. Lin-qi, Study on toughness modification of epoxy resin by polyurethane for crack repair in concrete," Journal of Highway and Transportation Research and Development, vol. 36, pp. 24-30, 2019.

[10] M. A. Safan, Z. A. Etman, and A. Konswa, "Evaluation of polyurethane resin injection for concrete leak repair," Case Studies in Construction Materials, vol. 11, Article ID e00307, 2019.

[11] J. W. Li and B. Z. Y. Qu, "Crack resistance test and application research of high toughness epoxy protective coatings under low temperature," Water Power, vol. 40, pp. 90-92, 2014.

[12] Y. Shen, Y. Wang, Y. Yang, Q. Sun, T. Luo, and H. Zhang, "Influence of surface roughness and hydrophilicity on bonding strength of concrete-rock interface," Construction and Building Materials, vol. 213, pp. 156-166, 2019.

[13] A. Naudts, "Irreversible changes in the grouting industry caused by polyurethane grouting: an overview of 30 Years of polyurethane grouting," in Proceedings of the 3nd International Specialty Conference on Grouting and Ground Treatment, pp. 1266-1280, New Orleans, LA, USA, February 2003.

[14] G. Lazzara, Y. Lvov, G. Cavallaro, R. Fakhrullin, and S. Konnova, "Composite films of natural clay nanotubes with cellulose and chitosan," Green Materials, vol. 2, no. 42, pp. 32-42, 2014.

[15] L. Xiaofang, Development of High-Efficiency Chemical Grouting Material for Dam, Hu Nan University, Changsha, China, 2001.

[16] C. Hai, T. Liu, and S. Xia, "Processing and analysis of chemical grouting for crack of concrete dam," Water Power, vol. 5, 2010.

[17] C. A. Apostolopoulos, K. F. Koulouris, and A. C. Apostolopoulos, "Correlation of surface cracks of concrete due to corrosion and bond strength (between steel bar and concrete)," Advances in Civil Engineering, vol. 2019, Article ID 3438743, 12 pages, 2019.

[18] I. Ghaaowd, J. S. McCartney, S. S. Thielmann, M. J. Sanders, and P. J. Fox, "Shearing behavior of tire-derived aggregate with large particle size. I: internal and concrete interface direct shear," Journal of Geotechnical and Geoenvironmental Engineering, vol. 143, no. 10, Article ID 04017078, 2017.

[19] L. I. Jing-wei, H. Ju-tao, and H. Ben-zheng, "Study on elastic polyurethane sealing material," Water Resourcs and Hydropower Engineering, vol. 11, 2005.

[20] Z. Sun and Y. Lu, "Underwater crack repairing technology for concrete dam," Water Power, vol. 11, pp. 65-67, 2002.

[21] Z. Jun, The Test and Research of the Polyurethane Sealing Material Bonding Performance in Channel Expansion Joint under the Special Construction Environment, Xinjiang Agricultural University, Ürümqi, China, 2016.

[22] Z. Fang, H.-q. Zhang, K.-y. Zhang, S.-h. He, and B. Tu, "Experimental research on bond performance of bond face between high-performance grouting materials and rock 
anchor," Journal of the China Railway Society, vol. 36, pp. 104-110, 2014.

[23] L. Eduarda and B. Lourenço Paulo, "Bond strength characterization of commercially available grouts for masonry," Construction and Building Materials, vol. 144, pp. 317-326, 2017.

[24] W. Luo, Y.-y. Xiao, H. E. Donger, and Z. Zhang, "Experimental study on interfacial tensile bonding performance of pre-heated CFRP-concrete under fast load," Engineering Mechanics, vol. 35, pp. 307-312, 2018.

[25] C. Yuan, W. Chen, T. M. Pham et al., "Effect of aggregate size on the dynamic interfacial bond behaviour between basalt fiber reinforced polymer sheets and concrete," Construction and Building Materials, vol. 227, Article ID 116584, 2019.

[26] Z. Zhenyu, W. Shanyong, and J. Feng, "Frictional behaviour of the interface between concrete and rubber: laboratory shear test and its elastoplastic model," Engineering Fracture Mechanics, vol. 197, pp. 192-205, 2018.

[27] L. Heng, F. Wang, and M. Shi, "Experimental and numerical simulation on bond behavior between polymer anchorage body and soil," Journal of Hydraulic Engineering, vol. 49, pp. 749-756, 2018.

[28] H. Liu, M. Shi, and F. Wang, "Experimental research on the bond strength between polyurethane polymer and steel bars," Chinese Journal of Underground Space and Engineering, vol. 12, pp. 1119-1225, 2016.

[29] Standard for test method of mechanical properties of ordinary concrete, Standard for Test Method of Mechanical Properties of Ordinary Concrete, China Planing Press, Beijing, China, 2002.

[30] S. Mingsheng, Research on Polymer Grouting Material Properties and Directional Fracturing Grouting Mechanism for Dykes and Dams, Dalian University of Technology, Dalian, China, 2011.

[31] S. Mingsheng, F. Wang, and J. Luo, "Compressive strength of polymer grouting material at different temperatures," Journal of Wuhan University of Technology: Materials Science English Edition, vol. 25, pp. 962-965, 2010.

[32] M. Wang Fu, M. S. Shi, H. J. Li, and Y. H. Zhong, "Experimental study on the anti-permeability properties of polymer grouting materials," Advanced Materials Research, vol. 284, pp. 284-286, 2011.

[33] G. Pompe, M. Brauer, J. Schweikle, B. Nagel Hupfer, and D. Lehmann, "Influence of the temperature profile in the interface on the bond strength of polyamide-polyurethane two-component tensile bars," Journal of Applied Polymer Science, vol. 100, pp. 4297-4305, 2010.

[34] R. S. Ghosh and V. M. Malhotra, "Use of superplasticizers as water reducers," Cement, Concrete and Aggregates, vol. 1, pp. 56-63, 1979.

[35] H. Fang, Z. Su, X. Li, F. Wang, and Y. Fu, "Interfacial bond performance between self-expansion polymer and concrete," Construction and Building Materials, vol. 270, Article ID 121459, 2020.

[36] R. Haddad and M. Haddad, "Predicting fiber-reinforced polymer-concrete bond strength using artificial neural networks: a comparative analysis study," Structural Concrete, vol. 22, no. 1, pp. 38-49, 2020. 